\title{
Alpha-2 Adrenoceptor Activation Inhibits Phencyclidine-Induced Deficits of Spatial Working Memory in Rats
}

\author{
William Marrs',3, Julie Kuperman ',3, Tahlin Avedian', Robert H Roth² and J David Jentsch*,' \\ 'Department of Psychology, University of California at Los Angeles, Los Angeles, CA, USA; '2Departments of Psychiatry and Pharmacology, Yale \\ University, New Haven, CT, USA
}

\begin{abstract}
N-methyl-D-aspartate (NMDA)/glutamate receptor antagonists, such as phencyclidine (PCP), induce behavioral abnormalities (locomotor hyperactivity, sensorimotor gating deficits, impairments of cognition) in animals that are thought to model aspects of schizophrenia. The administration of PCP increases noradrenaline transmission in the rat prefrontal cortex, a brain structure required for normal cognitive processes. Noradrenaline, in turn, works through a set of receptors that have themselves been implicated directly in NMDA antagonist-induced deficits; we recently reported that the alpha-2 agonist, clonidine, is effective at preventing PCP-induced deficits of working memory and visual attention in rats. Here, we further investigated the role for alpha- 2 adrenoreceptors in the effects of PCP on spatial working memory performance. The alpha- 2 agonist clonidine $(0.001-0.01 \mathrm{mg} / \mathrm{kg}$, subcutaneously (s.c.)) produced a significant amelioration of PCP-induced working memory deficits; the effects of PCP $(1.0 \mathrm{mg} / \mathrm{kg}$, s.c.), but not clonidine, were reduced in noradrenaline-depleted rats. In addition, the alpha-2A-preferring agonist guanfacine $(0.05-1.0 \mathrm{mg} / \mathrm{kg}$, s.c.) dose-dependently prevented the deficits of spatial working memory performance produced by PCP. Although the highly selective alpha-2 receptor antagonist, atipamezole (ATI), failed to affect spatial working memory on its own, at the doses studied $(0.1-0.5 \mathrm{mg} / \mathrm{kg}$, s.c.), it dramatically enhanced the working memory deficit produced by PCP. These data indicate that alpha-2 adrenoreceptors tonically inhibit PCP-induced deficits of spatial working memory, suggesting an important role for these receptors in cognitive deficits associated with NMDA receptor hypofunction.
\end{abstract}

Neuropsychopharmacology (2005) 30, I500-1510, advance online publication, 16 February 2005; doi: I0.1038/sj.npp. I300700

Keywords: clonidine; noradrenaline; cognition; NMDA

\section{INTRODUCTION}

The neural mechanisms mediating cognitive deficits in schizophrenia are far from clear. Although the hypotheses separately implicate dopaminergic, cholinergic, noradrenergic, serotonergic, glutamatergic, and/or GABAergic deficits in schizophrenia sympatomatology, it is very likely that the actual circuit dysfunction in psychotic disorders involves inter-related changes in each of these systems. Indeed, studies of the neurochemical and behavioral effects of NMDA antagonists support just such a notion.

NMDA/glutamate receptor antagonists, such as PCP and ketamine, trigger cognitive deficits with face validity for certain impairments of attention and memory in schizo-

*Correspondence: JD Jentsch, Department of Psychology, University of California at Los Angeles, PO Box 95 I 563, Los Angeles, CA 90095|563, USA, Tel: + I 310825 8258, Fax: + I 310206 5895,

E-mail: Jentsch@psych.ucla.edu

${ }^{3}$ These authors contributed equally to this work

Received 29 November 2004; revised and accepted 10 January 2005 Online publication: 12 January 2005 at http://www.acnp.org/citations/ Npp0 I | 405040557/default.pdf phrenia (Grottick and Higgins, 2000; Javitt and Zukin, 1991; Jentsch and Roth, 1999; Malhotra et al, 1996; Newcomer et al, 1999; Newcomer and Krystal, 2001; Verma and Moghaddam, 1996). Increasing evidence supports the notion that neurochemical changes secondary to NMDA receptor hypofunction directly mediate these cognitive deficits, inasmuch as pharmacologic strategies working on nonglutamatergic systems can be effective at alleviating cognitive impairments in NMDA antagonist-treated animals (Jentsch and Anzivino, 2004; Verma and Moghaddam, 1996). For example, activation of dopaminergic and cholinergic systems triggered by NMDA blockade mediate both behavioral and neurotoxic effects of PCP and related drugs (Kim et al, 1999; Verma and Moghaddam, 1996), and an overall increase in excitatory glutamatergic transmission is thought to link NMDA receptor hypofunction to altered function of these reticular systems (Moghaddam et al, 1997).

Recent work has implicated the noradrenergic system in behavioral alterations produced by NMDA antagonists. Both PCP and ketamine dramatically increase noradrenaline release and turnover in brain (Bowers and Morton, 1994; 
Deutch et al, 1987; Kubota et al, 1999a; Lorrain et al, 2003; Rasmussen et al, 1991). In a recent study, Harkin et al (2001) demonstrated that the potent alpha-2 agonist, clonidine, strongly attenuated NMDA antagonist-induced hyperlocomotion in mice, while the potent alpha-2 receptor antagonist, yohimbine, produced opposite effects; Swanson and Schoepp (2003)reported similar effects of clonidine in rats. Alpha-2 agonists appear to exert broad actions against NMDA antagonist-induced effects as we recently reported that the alpha-2 agonist, clonidine, was also effective at ameliorating deficits of spatial working memory and visuospatial attention elicited by administration of the NMDA antagonist PCP (Jentsch and Anzivino, 2004).

The reported cognitive-enhancing effects of clonidine in PCP-treated animals (Jentsch and Anzivino, 2004) may be predictive of effects on cognitive function in schizophrenia patients produced by alpha-2 agonists (Fields et al, 1988; Friedman et al, 2001). Although clonidine and related alpha-2 agonists such as guanfacine are not as active, clinically, as they are in preclinical models, there is sufficient evidence of procognitive effects of these drugs to warrant further study. We therefore designed the current set of experiments to explore (1) the dose-dependency of the effects of clonidine in PCP-treated animals, (2) the degree to which the actions of clonidine vary with respect to the integrity of the presynaptic noradrenergic system, (3) whether guanfacine, another alpha-2 agonist, also produces an attenuation of PCP-induced cognitive deficits similar to clonidine, and (4) if a highly selective alpha- 2 antagonist ATI produces effects opposite to those of clonidine.

\section{MATERIALS AND METHODS}

\section{Subjects}

Male and female Long-Evans rats (Harlan, Indianapolis IN) were used in these experiments. Subjects were housed into same-sex groups of two to three on a 14.5/9.5 h light/dark cycle. Training and testing were conducted only during the light phase.

The rats were 55-75 days old at the initiation of testing. Food restriction was initiated 3 days before training began, during which time they were exposed to small quantities of the reinforcer $(45 \mathrm{mg}$ Bio-Serv dustless precision pellets; Bio-Serv, Frenchtown, NJ). After training began, they were fed $\sim 10-15 \mathrm{~g} / \mathrm{rat}$ after the daily test sessions. Water was always available in the home cage. The experimental protocols used were consistent with the National Institutes of Health's Guide for the Care and Use of Laboratory Animals and were approved by the Chancellor's Animal Research Committee at the University of California, Los Angeles.

\section{Behavioral Testing Apparatus}

The design of the behavioral testing chambers is based upon that described by Carli et al (1983). The apparatus (Model MED-NPW-9L; MED Associates, St Albans, VT) is an extratall aluminum and Plexiglas operant conditioning chamber. On one wall of the chamber is a pellet delivery magazine equipped with a cup light and an infrared beam sensor. The wall opposite the magazine is curved and is fitted with five nose-poke apertures, each of which is equipped with an internal LED lamp and an infrared beam sensor. The chambers are housed in sound-attenuating cubicles with background white noise broadcast during the session and are illuminated by a house light (a light diffuser placed outside the chamber, but inside the cubicle).

\section{Initial Training}

Training started with a single $45 \mathrm{~min}$ session of magazine training, during which the house light was on constantly and pellets were delivered into the magazine on a fixed-time 20 -s schedule. On the second day of training, rats were reinforced with a single food pellet for making a nose-poke response into an illuminated aperture. With the house light on, an aperture was selected at random and illuminated for up to $30 \mathrm{~s}$. If the rat made a response (nose poke) into the illuminated aperture before the $30 \mathrm{~s}$ expired, the aperture light was extinguished, the magazine was illuminated, a pellet was delivered, and a correct response was recorded. An entry into the magazine would extinguish the magazine light and initiate the start of a new trial $5 \mathrm{~s}$ later. If, instead, the rat made a response into an unlit aperture, an incorrect choice would be scored, a 3-s time out would ensue, and a new trial would begin $5 \mathrm{~s}$ later. If the rat failed to respond during stimulus presentation, an omission would be recorded, a time out would be initiated, and a new trial would begin $5 \mathrm{~s}$ later. Each session terminated after 100 trials were completed or after $45 \mathrm{~min}$ elapsed, whichever came first. Each rat was trained on this procedure until it reached a session accuracy of at least $80 \%$ (accuracy was defined as the number of correct responses divided by the total number of correct and incorrect responses) with no more than $20 \%$ omissions (total number of omissions as a proportion of all trials).

After meeting the aforementioned criterion, the duration of illumination of the nose-poke aperture on individual trials was reduced to $5 \mathrm{~s}$. As above, a response into the illuminated aperture during signal presentation resulted in a food pellet being delivered, while an incorrect response (into a darkened aperture) or no response within the 5-s period led to a time out. Each rat was again trained until achieving an accuracy of at least $80 \%$ with no more than $20 \%$ omission, after which it was advanced to the delayed nonmatch-to-sample task.

\section{Delayed Nonmatch-to-Sample Training}

Each trial in the delayed nonmatch-to-sample task consisted of both a sample phase and a choice phase. During the sample phase, one aperture is illuminated temporarily, followed by a delay period in which all aperture lights are extinguished. After the delay, two apertures are illuminated (including the sample hole) and the rats' job is to nonmatch, or respond into the aperture not illuminated during the sample phase. The inter-trial interval was $5 \mathrm{~s}$, and the task ended after 125 trials were completed or 60 min passed, whichever came first. The task utilized here is operationally similar to a recent task described by Chudasama and Robbins (Chudasama et al, 2004; Chudasama and Robbins, 2004a), with the exception that 
their task uses shorter stimulus durations (to tax attentional processes) and involves a match contingency.

In the sample phase, one of the five apertures was chosen at random and illuminated for up to $5 \mathrm{~s}$. A response into the illuminated aperture (correct sample-phase choice) caused the aperture light to extinguish and the magazine to be illuminated. The magazine remained lit until an entry into the magazine was detected, after which the choice phase was initiated (see below). Alternatively, a response in an unlit nose-poke aperture (incorrect sample-phase choice) or a failure to respond within $5 \mathrm{~s}$ (sample-phase omission) resulted in the trial being aborted, and a $5 \mathrm{~s}$ time-out period ensued.

During the choice phase of the trial, two apertures were illuminated: the sample aperture (the match location) and a new aperture selected at random (the nonmatch location). Both of these apertures were illuminated for up to $15 \mathrm{~s}$. A response in any aperture other than that of the nonmatch location would result in a 5-s time out, and an incorrect response would be recorded. Failure to make a response within $15 \mathrm{~s}$ would result in a time out. Responses to the nonmatch location triggered magazine illumination, and in some cases, pellet delivery. All correctly completed trials that followed a correctly completed trial were reinforced, while none of the correctly completed trials that followed an incorrectly completed trial were reinforced. At $5 \mathrm{~s}$ after entry into the magazine, a new trial would commence.

For all completed trials, the actual interval between the response in the sample phase and the response in the choice phase was considered to be the trial-specific 'delay'. This means that the range of encountered delays could vary from animal to animal during training. During training, trials were binned according to delay to evaluate the relationship between delay and performance.

In order to standardize encountered delays on treatment days, we implemented sessions in which 'minimum' delay periods were enforced. The minimum delays were either 0 , 5 , or $10 \mathrm{~s}$, and the delay period administered was selected at random from trial to trial. On nontreatment days, animals were tested on the free delay period described above.

\section{Experiment 1}

In this experiment, we sought to determine whether the cognitive-enhancing effects of the alpha-2 agonist, clonidine, in PCP-treated animals (Jentsch and Anzivino, 2004) was altered by prior exposure to a noradrenergic neurotoxin. To address this issue, rats were trained to perform the spatial working memory task before being distributed into two groups (with similar numbers of male and female subjects in each group), based upon their baseline performance measures; they were subsequently treated with either saline $(2 \mathrm{ml} / \mathrm{kg}$, i.p.) or the noradrenergic neurotoxin $\mathrm{N}$-(2-chloroethyl)- $\mathrm{N}$-ethyl-2-bromobenzylamine hydrochloride (DSP-4; $40 \mathrm{mg} / \mathrm{kg}$ in $2 \mathrm{ml} / \mathrm{kg}$ saline, i.p.; Sigma, St. Louis MO). This dosage of DSP-4 was chosen because of its ability to produce a neurochemically selective but substantial reduction in forebrain tissue noradrenaline levels (Tellez et al, 1999).

At 7 days after DSP-4 injection, testing was resumed, and several baseline sessions were delivered in order to determine whether any performance differences could be measured that were related directly to DSP-4 treatment. After this baseline period, the effects of clonidine $(0,0.001$, or $0.01 \mathrm{mg} / \mathrm{kg}$ ) and PCP (0 or $1.0 \mathrm{mg} / \mathrm{kg}$ ) were determined using a $3 \times 2$ within-subject design. Clonidine (as the hydrochloride; Sigma) and PCP (as the hydrochloride; Sigma) were dissolved in $0.9 \%$ sterile saline and injected s.c. at $30 \mathrm{~min}$ and $10 \mathrm{~min}$ prior to testing, respectively. The order of doses was determined by a cyclic Latin square design. The ordering of doses was balanced across the two groups (control vs DSP-4), and 3-4 days of drug-free training separated each drug challenge.

After completion of the behavioral tests conducted above, conscious rats were killed, during the light phase, by rapid decapitation. Brains were extracted, and the prefrontal cortex was dissected on a cold platform and immediately stored at $-80^{\circ} \mathrm{C}$. The tissue samples were later analyzed by high-pressure liquid chromatography with electrochemical detection (HPLC-EC) precisely as described previously (Jentsch et al, 1997b). Tissue protein levels were determined spectrophotometrically according to Lowry's method (Lowry et al, 1954). Total tissue levels of noradrenaline, dopamine, and serotonin (in ng) were calculated and expressed as a proportion of the total protein content of the sample.

\section{Experiment 2}

In Experiment 2, the degree to which an alpha-2Apreferring agonist could mimic the ability of clonidine to attenuate PCP-induced deficits of spatial working memory was assessed. A total of 12 rats were used to evaluate whether guanfacine hydrochloride (Sigma) blocked deficits of spatial working memory performance induced by PCP. Rats were treated with $0.9 \%$ saline or guanfacine $(0.5$ or $1.0 \mathrm{mg} / \mathrm{kg}$, s.c.) $30 \mathrm{~min}$ prior to testing, followed by $0.9 \%$ saline or PCP $(1.0 \mathrm{mg} / \mathrm{kg}$, s.c.) $10 \mathrm{~min}$ prior to testing. The order of treatment conditions were given in a cyclic Latin square design (within-subject design), and at least 3-4 days of drug-free training separated each drug challenge. Based upon the substantial sedating effects of these higher doses of the drug, a follow-up study was executed in which saline or lower doses of guanfacine $(0.05$ or $0.1 \mathrm{mg} / \mathrm{kg}$, s.c.) were used as a pretreatment to saline or PCP $(1.0 \mathrm{mg} / \mathrm{kg}$, s.c. $)$. Again, the orders of treatments were given in a cyclic Latin squares design, and 3-4 days of drug-free training separated each drug challenge.

\section{Experiment 3}

Experiment 3 was designed to evaluate whether an alpha-2 receptor antagonist could alter PCP-induced deficits of spatial working memory in a manner symmetrical to that produced by the alpha- 2 agonist clonidine. The effects of the alpha-2-selective antagonist ATI (Orion-Pharma, Turku, Finland) given alone, or in combination with PCP, on spatial working memory performance were determined in a set of nine rats. For these subjects, saline $(1 \mathrm{ml} / \mathrm{kg})$ or ATI $(0.1$ or $0.5 \mathrm{mg} / \mathrm{kg})$ was administered s.c. $30 \mathrm{~min}$ prior to testing (doses based upon Millan et al, 2000), followed by an injection of saline or PCP $(1.0 \mathrm{mg} / \mathrm{kg}) 10 \mathrm{~min}$ prior to test. All rats received all treatments, the order of which was 
balanced using a cyclic Latin square design, and 3-4 days of drug-free training separated each drug challenge.

\section{Data Analysis}

Data from the behavioral experiments were analyzed with repeated measures analysis of variance (ANOVA). For each session, multiple delays were imposed, and therefore, delay was factored in as the repeated measure for the analyses of response accuracy. In addition, all pharmacological studies were within-subject designs, so treatment conditions (eg saline $v s$ guanfacine $0.05 v s$ guanfacine 0.1 ) were likewise treated as repeated measures. Between-subject factors included sex and group (control vs DSP-4), where appropriate. Post hoc comparisons included Tukey's tests when permitted by the presence of a significant main effect or interaction.

Data from the post-mortem neurochemical experiments were analyzed by unpaired $t$-tests to confirm group differences in the three parent amine levels.

\section{RESULTS}

\section{Experiment 1: Clonidine + PCP Effects in DSP-4-Treated Animals}

Baseline performance. After training on the delayed nonmatch-to-sample task, rats were treated systemically with saline ( $2 \mathrm{ml} / \mathrm{kg}$, i.p.) or DSP-4 $(40 \mathrm{mg} / \mathrm{kg}$, i.p.). They were first tested 10 days after toxin treatment to determine whether a reduction in forebrain noradrenaline affected baseline working memory performance. As expected, ANOVA revealed a highly significant main effect of delay $\left(\mathrm{F}_{(2,28)}=10.3, p<0.001\right)$; performance ranged from $\sim 85-$ $90 \%$ at delays less than $5 \mathrm{~s}$ to between $\sim 70$ and $75 \%$ at delays more than $10 \mathrm{~s}$, supporting the validity of the test as a measure of working memory. At 10 days after toxin treatment, there were no measured differences between DSP-4 and control rats for choice accuracy (Figure 1), as revealed by no main effect of group or no group $\times$ delay interaction. Additionally, there were no main effects of sex or no higher level interactions involving sex for response accuracy (Figure 1). The lack of effect of DSP-4 treatment on working memory performance, which is generally consistent with earlier observations by Wenk et al (1987), persisted for the duration of testing (more than 60 days; see Figure 2).

At 10 days after DSP-4 exposure, omission rates (either for the sample or choice phases) were also not affected by sex $($ F's $<1)$ but were affected by DSP-4 treatment (sample omissions: $\mathrm{F}_{(1,14)}=14.6, \quad p=0.002$; choice omissions: $\left.\mathrm{F}_{(1,14)}=5.1, p<0.05\right)$. Both main effects of DSP-4 treatment were mediated by significant reductions in omissions in the depleted animals, relative to normal control rats. The effects of DSP-4 treatment on omissions did not vary with respect to sex.

Clonidine/PCP effects on choice accuracy. Subsequently, the rats were challenged with clonidine $(0,0.001 \mathrm{mg} / \mathrm{kg}$ or $0.01 \mathrm{mg} / \mathrm{kg}$, i.p.) followed by PCP (0 or $1 \mathrm{mg} / \mathrm{kg}$, s.c.) in a $3 \times 2$ within-subject design (Figure 2). Overall repeated measures ANOVA revealed main effects of delay

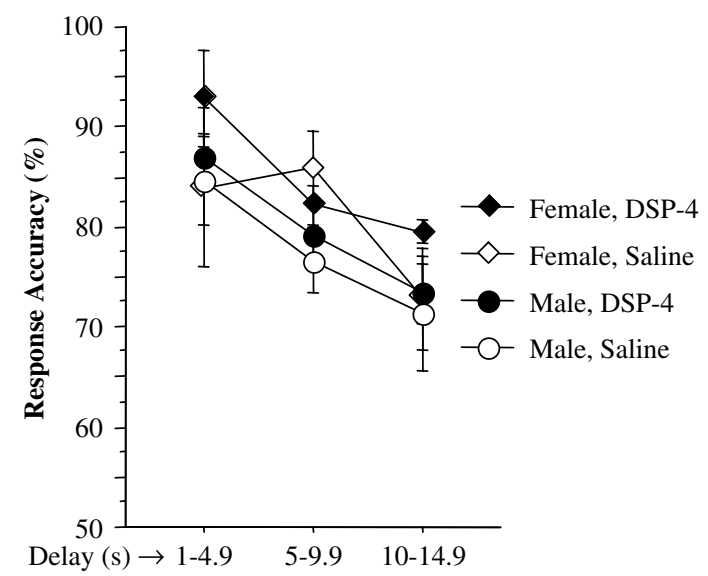

Figure I Curves describing the response accuracy-delay function for male and female rats exposed to either saline (as a control) or DSP-4 $(40 \mathrm{mg} / \mathrm{kg}$, i.p.; to reduce forebrain noradrenaline levels). Testing was conducted 10 days after the dosing. No main effects of sex or treatment group were apparent, indicating that the amount of noradrenaline depletion produced in this experiment did not affect working memory performance, on its own. Data represent means $\pm S E M$. Significant differences between saline and PCP-treated rats are indicated as follows: **** $p<0.000$ I; $*$ $p<0.05 . N=9$ control rats; $N=9$ DSP-4 rats.

$\left(\mathrm{F}_{(2,30)}=52.1, \quad p<0.0001\right)$, as well as effects of both clonidine dose $\left(\mathrm{F}_{(2,30)}=6.3, p<0.01\right)$ and PCP treatment $\left(\mathrm{F}_{(1,15)}=51.2, p<0.0001\right)$. There was a statistically significant interaction between clonidine dose and PCP dose $\left(\mathrm{F}_{(2,30)}=4.0, p<0.05\right)$. Based upon the clonidine dose $\times$ PCP treatment interaction, follow-up ANOVA were performed to determine whether PCP evoked a deficit, relative to saline challenge, after saline, clonidine $0.001 \mathrm{mg} /$ $\mathrm{kg}$, or clonidine $0.01 \mathrm{mg} / \mathrm{kg}$. These analyses revealed that PCP treatment significantly impaired performance in rats pretreated with saline (Figure $2 \mathrm{a} ; \mathrm{F}_{(1,17)}=30.9, p<0.0001$ ) and $0.001 \mathrm{mg} / \mathrm{kg}$ clonidine (Figure 2b; $\mathrm{F}_{(1,16)}=14.7$, $p<0.01$ ) but not $0.01 \mathrm{mg} / \mathrm{kg}$ clonidine (Figure 2c). These data support our earlier report that PCP impairs working memory performance and that clonidine dose-dependently attenuates this effect (Jentsch and Anzivino, 2004).

Overall ANOVA also revealed a significant PCP treatment $\times$ group interaction $\left(\mathrm{F}_{(1,15)}=8.5, p<0.01\right)$, in the absence of a clonidine dose $\times$ group interaction. This interaction indicates that DSP-4 treatment altered the behavioral effects of PCP but not clonidine. In rats not receiving clonidine, PCP evoked a performance deficit in both control $(p<0.001)$ and DSP-4-pretreated $(p<0.05)$ rats; however, the drug-induced decline in performance was less substantial in DSP-4-pretreated rats than in control subjects.

In this experiment, there were no main effects of sex or no higher level interactions involving sex, for the choice accuracy measure (all F's $<1$ ). Therefore, sex did not affect response accuracy, which is related to spatial working memory performance, nor did it affect the response to clonidine or PCP.

Clonidine/PCP effects on omissions. Clonidine, within this dose range, sedated the subjects, while PCP stimulated them (Figure 3). Considering first sample omissions (Figure 3a), repeated measures ANOVA revealed separate main effects 

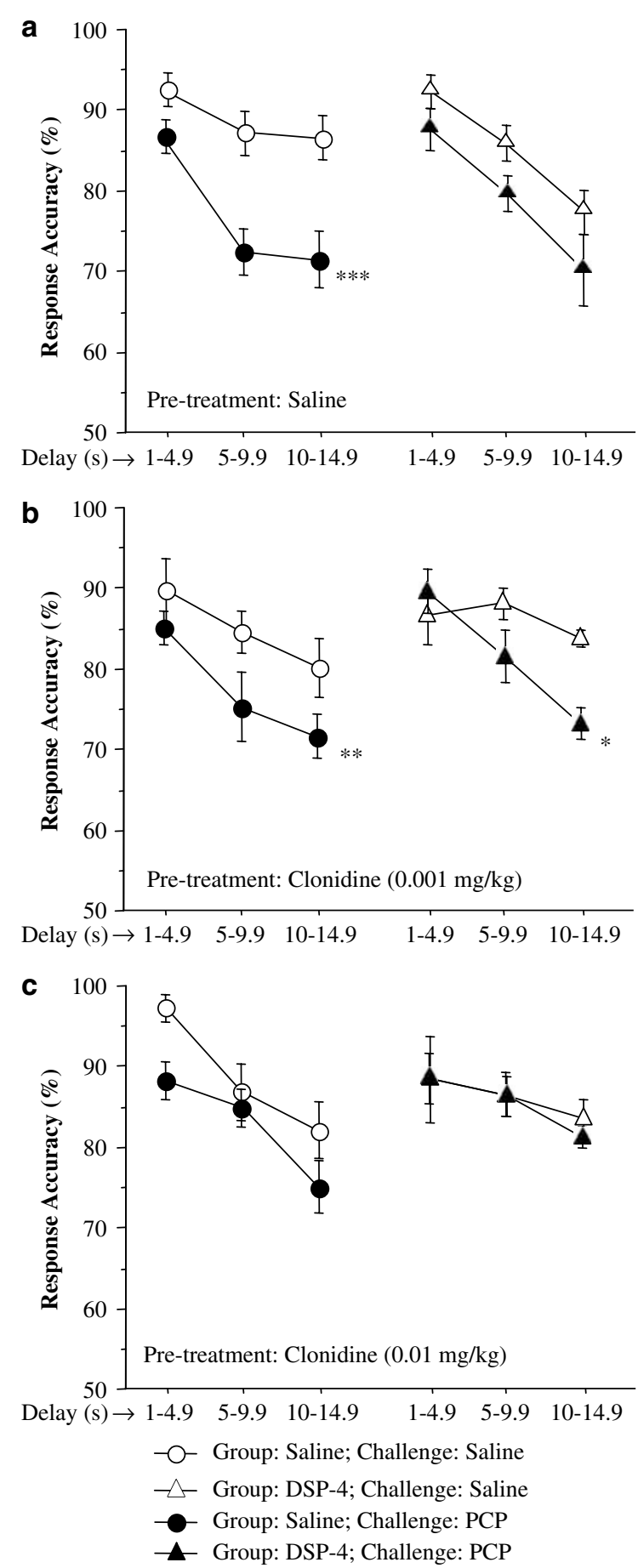

Figure 2 Clonidine $(0,0.00 \mathrm{l}$, or $0.01 \mathrm{mg} / \mathrm{kg}, \mathrm{s.c}$.$) and \mathrm{PCP}(0$ or 1.0 $\mathrm{mg} / \mathrm{kg}$, s.c.) were administered alone, and in combination, to control rats or to subjects previously treated with DSP-4 $(40 \mathrm{mg} / \mathrm{kg}$, i.p.) to decrease forebrain noradrenaline concentrations (Table I). PCP impaired response accuracy in the spatial working memory test, and clonidine dosedependently reversed that deficit. PCP appeared to elicit a less substantial deficit of working memory in DSP-4 relative to control rats. Data are not split by sex due to no significant effects of sex or interactions involving sex. Data represent means + SEM. Significant differences between saline and PCP-treated rats are indicated as follows: $* * * * 2<0.0001$; $* * * 0.01$; $* 2<0.05 . N=9$ control rats; $N=9$ DSP-4 rats.

of $\operatorname{sex}\left(\mathrm{F}_{(1,14)}=13.5, p=0.003\right)$, clonidine dose $\left(\mathrm{F}_{(2,28)}=\right.$ 43.0, $p<0.0001)$, and PCP dose $\left(\mathrm{F}_{(1,14)}=22.9, p<0.001\right)$; these main effects did not interact, nor did group (control $v s$
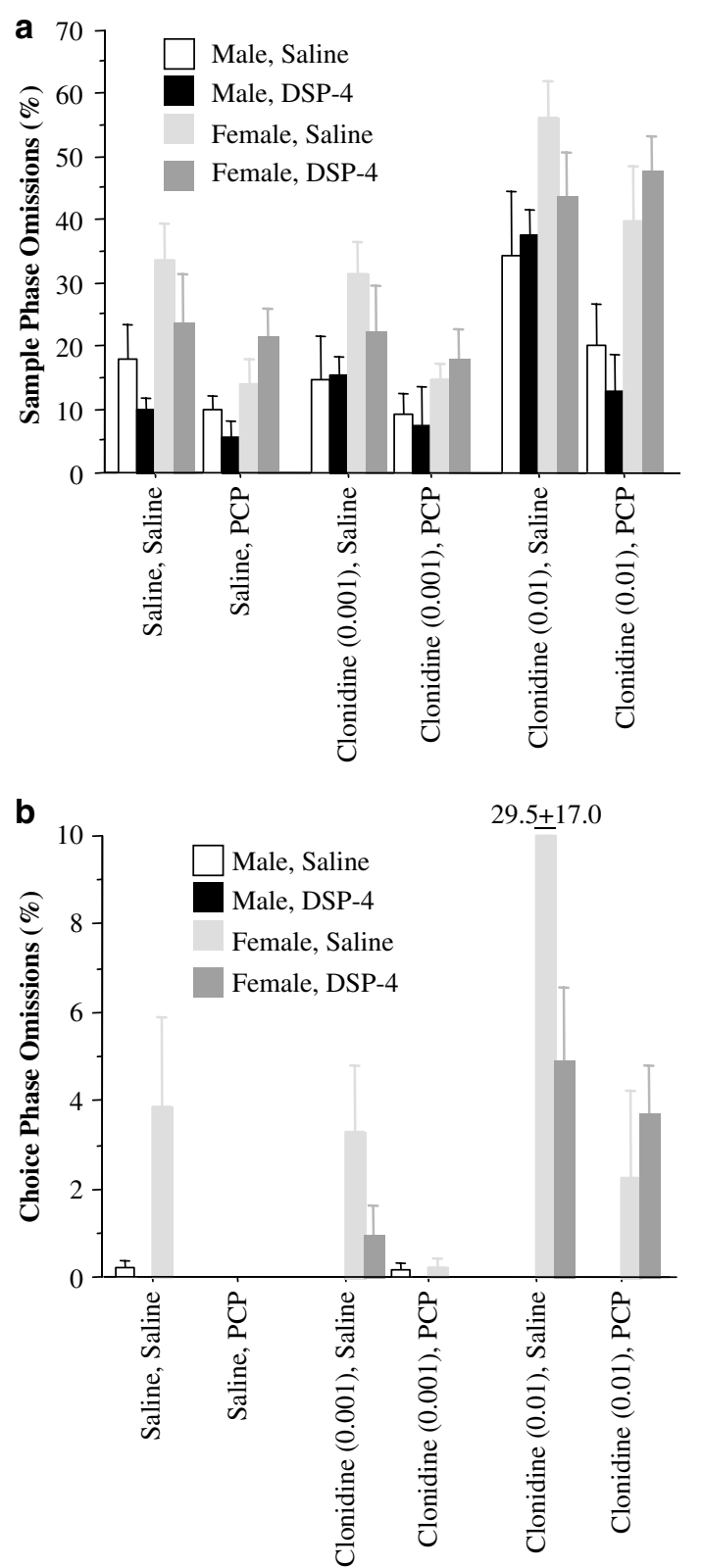

Figure 3 Female rats made more sample-phase omissions than male rats, and clonidine increased, while PCP decreased, these omissions. Sedating effects of clonidine were limited to the highest dose $(0.01 \mathrm{mg} / \mathrm{kg}$, s.c.). Although more rare in frequency, choice-phase omissions were also affected by sex (females made more omissions than males), clonidine (dose-dependent increase), and PCP (reduction). Data represent means \pm SEM. $N=9$ control rats; $N=9$ DSP-4 rats.

DSP-4) enter into any significant interactions. Overall, females made more sample-phase omissions than males, clonidine dose-dependently increased omission rates (only the $0.01 \mathrm{mg} / \mathrm{kg}$ dose differed from saline, $p<0.0001$ ), and PCP decreased omission rates.

Repeated measures ANOVA were next performed on omission rates in the choice phase (Figure $3 \mathrm{~b}$ ). Choicephase omissions were much rarer than sample omissions, occurring with a frequency of $<4 \%$ at baseline. Main effects of sex $\left(\mathrm{F}_{(1,14)}=6.1, p<0.05\right)$, clonidine dose $\left(\mathrm{F}_{(2,28)}=5.8\right.$, $p<0.01)$, and PCP dose $\left(\mathrm{F}_{(1,14)}=4.7, p<0.05\right)$ were 
revealed, along with a statistically significant sex $\times$ clonidine dose interaction $\left(\mathrm{F}_{(2,28)}=5.9, p<0.01\right)$. Essentially, females made more omissions than males, clonidine dose-dependently increased omissions in both males and females (only the $0.01 \mathrm{mg} / \mathrm{kg}$ dose different from saline; $p<0.01$ ), and clonidine more strongly increased omissions in females. An additional clonidine dose $\times$ PCP dose interaction $\left(\mathrm{F}_{(2,28)}=3.9, p<0.05\right)$ indicated that PCP reduced the increase in omissions produced by clonidine.

Group (control vs DSP-4) did not affect omission rates or enter into any interactions with other factors for omissions, unlike what was found at 10 days post-DSP-4. This suggests that the suppression of omissions found at the earlier time point was a transient effect of noradrenaline depletion.

Confirmation of DSP-4-induced noradrenergic depletion. After completion of the behavioral testing, the rats were killed and monoamine levels were measured in the prefrontal cortex using HPLC-EC. As predicted, $\sim 60$ days after DSP-4 treatment $(40 \mathrm{mg} / \mathrm{kg})$, prefrontal cortical noradrenaline levels were substantially $(\sim 50 \%)$ but selectively decreased (Table $1 ; p<0.0001$. by unpaired $t$-test); dopamine and serotonin levels were not significantly affected (Table 1; NS).

\section{Experiment 2: Guanfacine + PCP Effects on Spatial Working Memory}

Guanfacine $(0.5$ and $1.0 \mathrm{mg} / \mathrm{kg})$. In order to further evaluate whether alpha-2 agonists, as a class, attenuate the deleterious effects of PCP on working memory, we also assessed the effects of the alpha- 2 agonist guanfacine in a separate, experimentally naive cohort of rats $(n=6$ males and $n=6$ females). Guanfacine has slightly higher affinity for the alpha-2A vs alpha-2B and alpha-2C receptors (Uhlen et al, 1995, 1997a).

Initially, the effects of guanfacine $(0.05-1.0 \mathrm{mg} / \mathrm{kg}$, s.c.) pretreatment on PCP-induced deficits of spatial working memory were investigated. Both doses of guanfacine exerted sedating effects, complicating interpretation of their effects on spatial working memory per se. For these two higher doses, there was a main effect of guanfacine $\left(\mathrm{F}_{(2,11)}=105.0, p<0.0001\right)$ and a main effect of PCP $\left(\mathrm{F}_{(1,11)}=5.3, p<0.05\right)$ for total trials completed (Figure 4). Post hoc analyses confirmed that the main effect of guanfacine was driven by a dose-dependent decrease in the number of trials completed (several of the rats treated with the highest dose of guanfacine fell asleep during the 30 min drug-to-testing interval); the main effect of PCP

Table I Tissue Monoamine Levels from Rats Treated with Vehicle or DSP-4 (40 mg/kg, i.p.)

\begin{tabular}{llccc}
\hline Group & Brain Region & Noradrenaline & Dopamine & Serotonin \\
\hline DSP-4 & Prefrontal cortex & $2.3 \pm 0.1$ ***** & $1.2 \pm 0.2$ & $6.3 \pm 0.4$ \\
Control & Prefrontal cortex & $4.6 \pm 0.1$ & $1.2 \pm 0.1$ & $6.3 \pm 0.2$ \\
\hline
\end{tabular}

All values are ng analyte/mg protein.

****ignificantly different than control levels, $p<0.0001$.
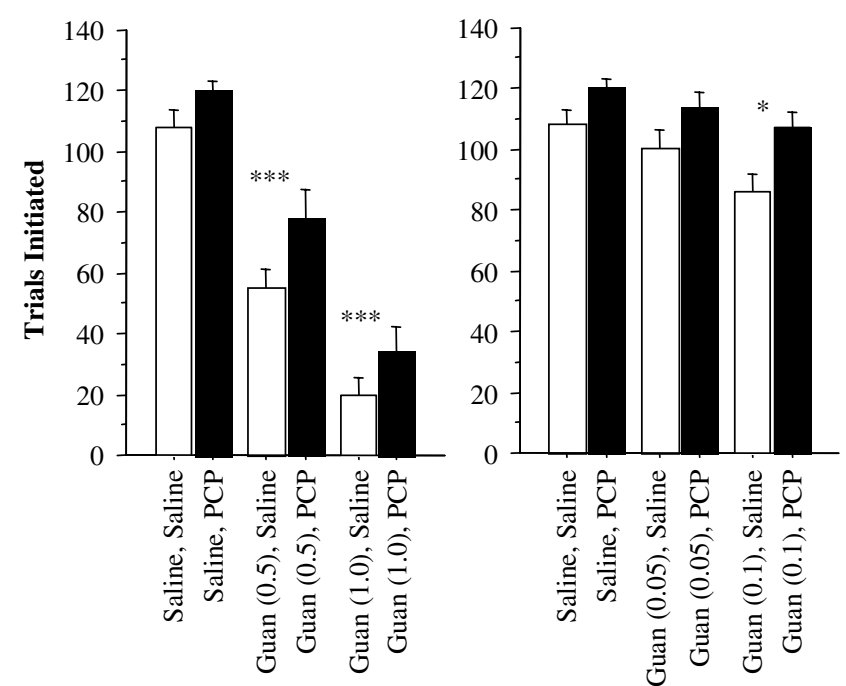

Figure 4 In two subsequent experiments, guanfacine was shown to dose-dependently suppress the total number of trials initiated by rats, evidence for substantially sedative effects of the drug. Doses of $0.1 \mathrm{mg} / \mathrm{kg}$ (s.c.) and higher reduced the total number of trials initiated. The lowest dose of guanfacine studied $(0.05 \mathrm{mg} / \mathrm{kg}$, s.c.) did not significantly affect this measure. Data represent means \pm SEM. Significant differences between saline and guanfacine-treated rats are indicated as follows: **** $p<0.000$ I; ${ }^{*} p<0.05 . N=12$ rats (six males, six females) received all treatments in a within-subject design.

reflected an overall increase in the number of trials completed by animals treated with the NMDA antagonist. These two main effects appeared to be purely additive with one another.

The decrease in trials completed produced by guanfacine was associated with a main effect of agonist treatment for omissions during both the sample phase $\left(\mathrm{F}_{(2,22)}=23.6\right.$, $p<0.001)$ and choice phase $\left(\mathrm{F}_{(2,10)}=4.9, p<0.01\right.$; one animal was excluded from this analysis because it initiated no trials after $1 \mathrm{mg} / \mathrm{kg}$ of guanfacine). In other words, the high doses of the alpha-2 agonist decreased the numbers of trials initiated and increased the total number of omissions. Owing to the substantial sedation produced by guanfacine, no clear conclusions about the effects of the high doses on cognitive performance could be drawn.

Guanfacine $(0.05$ and $0.1 \mathrm{mg} / \mathrm{kg}) / P C P$ effects on choice accuracy. The experiment was subsequently repeated in the same rats, using 0.05 and $0.1 \mathrm{mg} / \mathrm{kg}$ of guanfacine $v s$ PCP $(1.0 \mathrm{mg} / \mathrm{kg})$. Main effects of guanfacine dose $\left(\mathrm{F}_{(2,22)}=11.2\right.$, $p<0.001)$ and PCP treatment $\left(\mathrm{F}_{(1,11)}=8.8, p<0.01\right)$ were again detected for trials completed (Figure 4 ). The main effect of guanfacine dose was due to a dose-dependent reduction in trials initiated; post hoc comparisons demonstrated that only the $0.1 \mathrm{mg} / \mathrm{kg}$ dose differed from saline. The reduction in trial completion was not confounding for either dose because all subjects still performed a large enough number of trials $(>80)$ to permit adequate analyses to be conducted.

Figure $5 \mathrm{a}$ displays the effects of $0.05-0.1 \mathrm{mg} / \mathrm{kg}$ of guanfacine on PCP-induced deficits of choice accuracy in the spatial working memory task. Repeated measures ANOVA revealed a main effect of PCP treatment $\left(\mathrm{F}_{(1,10)}=5.4, p<0.05\right)$, which statistically interacted with 

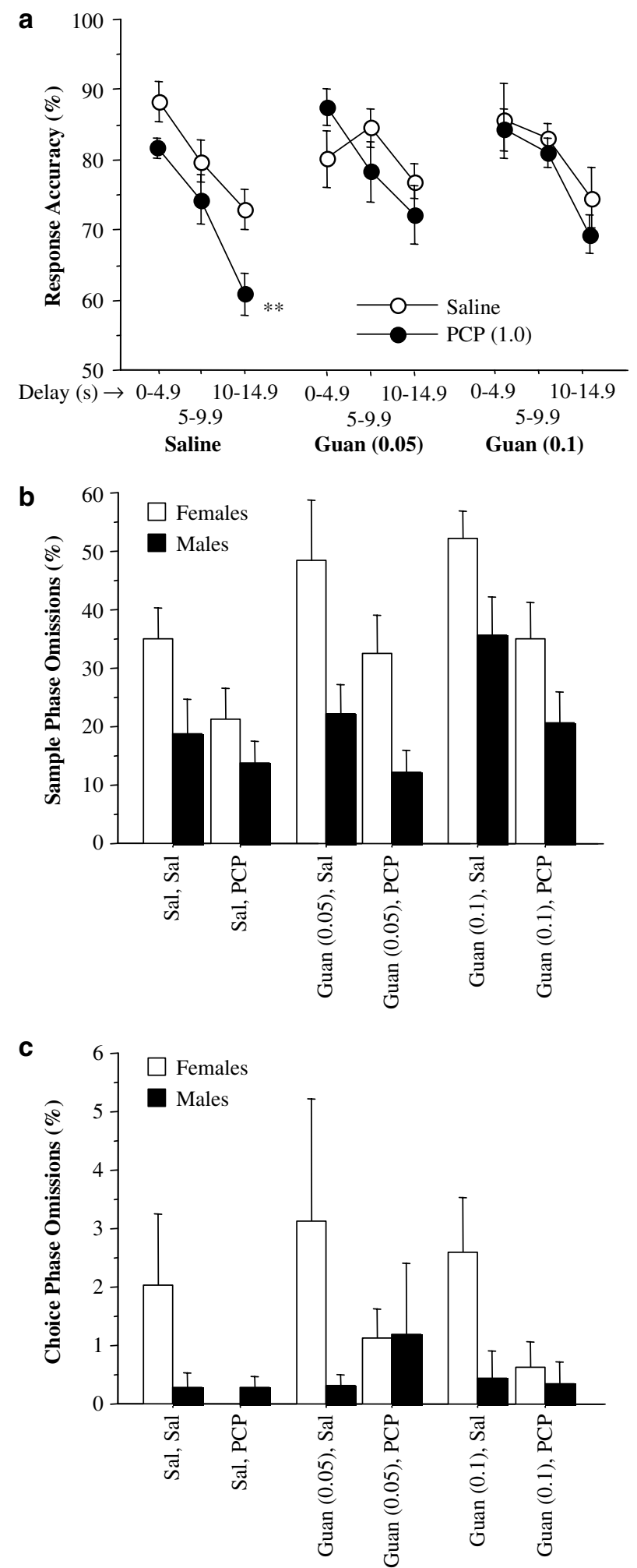

Figure 5 Choice accuracy and omissions were affected by guanfacine and PCP treatments. PCP impaired choice accuracy and reduced omissions, while guanfacine blocked the deficit in working memory performance while increasing omission rates. Data represent means $\pm S E M$. Significant differences between saline and PCP-treated rats are indicated as follows: ${ }^{*} * 0<0.01 . N=12$ rats (six males, six females) received all treatments in a within-subject design. 

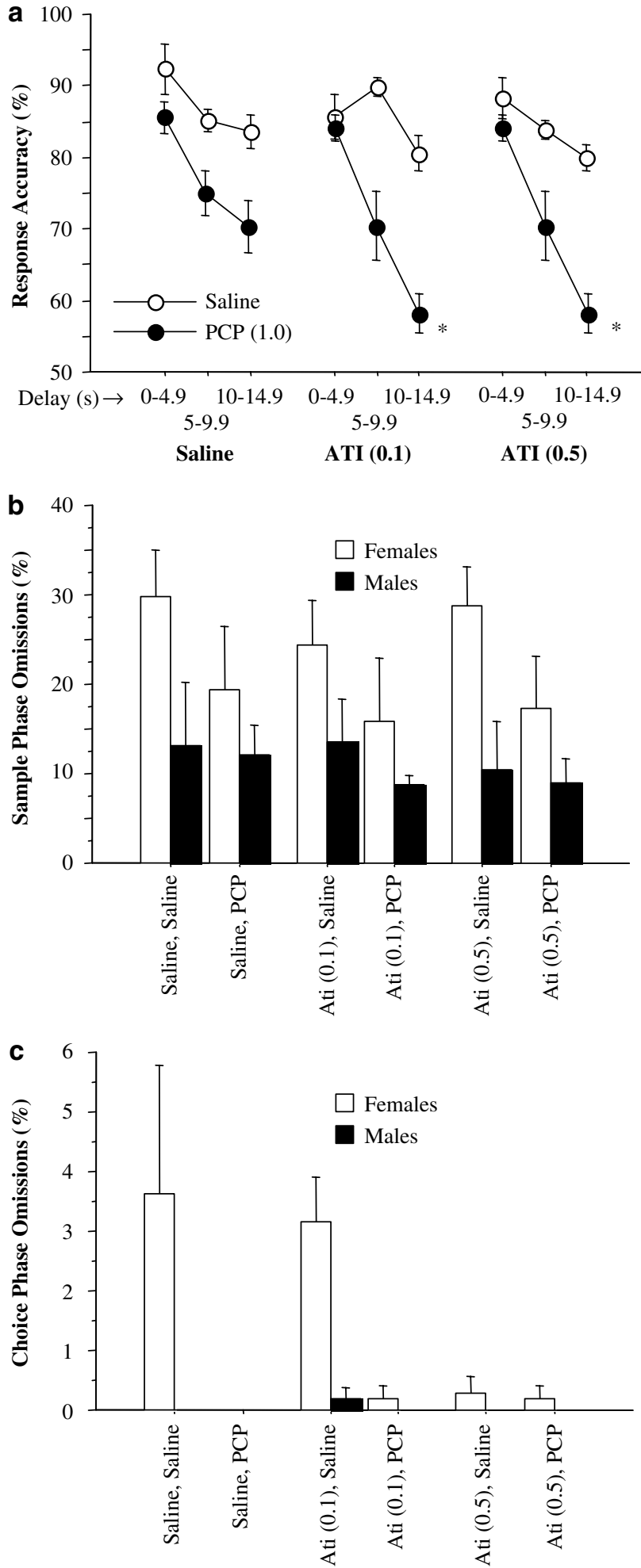

Figure 6 ATI augmented the deficits of choice accuracy produced by PCP. There were no drug interactions measured for omissions. Data represent means \pm SEM. Significant differences between saline and ATItreated rats are indicated as follows: $* p<0.05 . N=12$ rats (six males, six females) received all treatments in a within-subject design.

selective alpha-2 receptor antagonist ATI. These data indicate that alpha-2 receptors tonically inhibit NMDA antagonist-induced deficits of cognition. Our hypothesis is that the increased release of noradrenaline that occurs after PCP administration (Bowers and Morton, 1994; Deutch et al, 1987; Kubota et al, 1999a) contributes directly to the cognitive deficits produced by the NMDA antagonist; this view is supported by the interaction between group (control $v s$ DSP-4) and PCP dose, which was mediated by diminished PCP effects in animals (DSP-4 treated) with a compromised noradrenergic system.

Using a match variant of the task employed here, Chudasama and Robbins (2004a) also provided evidence for an important neuromodulatory influence of dopamine D1 agonists in working memory performance. PCP also evokes the release of dopamine into the prefrontal cortex (Bowers and Morton, 1994; Deutch et al, 1987; Hertel et al, 1995), and clonidine is effective at suppressing dopaminergic hyperactivity evoked by PCP (Jentsch et al, 1998). Taken together, these neurochemical and behavioral data indicate that a role for dopamine in the current results must also be considered.

\section{Opposite Effects of Alpha-2 Agonists and Antagonists}

As we reported previously, clonidine, at a dose of $0.01 \mathrm{mg} /$ $\mathrm{kg}$, attenuates PCP-induced deficits of working memory (Jentsch and Anzivino, 2004); this effect is found here to be dose-dependent, in that a 10 -fold lower dose is without significant effect. The higher dose of clonidine studied here did produce sedation, while a lower dose $(0.001 \mathrm{mg} / \mathrm{kg})$ was neither effective against PCP nor sedating. Guanfacine, on the other hand, prevented PCP-induced deficits of working memory at a dose $(0.05 \mathrm{mg} / \mathrm{kg})$ that produced only minimally sedating effects. Of course, the dose-response curve for guanfacine employed smaller increments, so it may be that a dose between 0.001 and $0.01 \mathrm{mg} / \mathrm{kg}$ of clonidine is effective against PCP effects while also being nonsedating. This issue deserves further attention.

A concern related to these findings emerges from a report by Millan and colleagues (Newman-Tancredi et al, 1998); both clonidine and guanfacine exhibit weak to moderate 5HT1A agonist properties (measured by actions on recombinant human receptors expressed in CHO cells) (NewmanTancredi et al, 1998). Taken with the fact that many conventionally used alpha- 2 antagonists (such as yohimbine and idazoxan) also exhibit actions at this receptor, the potential role for 5-HT1A in the cognitive effects of clonidine and guanfacine is worth considering. To address this, we show that the alpha-2 antagonist, ATI, which is highly selective for alpha-2 receptors (Newman-Tancredi et al, 1998), enhanced the effects of PCP on working memory performance. Therefore, a drug that acts as an alpha-2 antagonist, but which lacks any actions on the 5HT1A receptor, produces behavioral changes opposite to those produced by clonidine and guanfacine, thereby bolstering the claim that these are alpha-2 receptormediated effects.

\section{Involvement of Presynaptic Noradrenergic Mechanisms?}

Alpha-2 receptors are found on both presynaptic axonal terminals and on postsynaptic targets (Aoki et al, 1994, 1998). Presynaptically, they can act as both autoreceptors and heteroreceptors (Cooper et al, 2003). One prominent 
idea is that they may work presynaptically to suppress hypernoradrenergic function induced by NMDA antagonists (Bowers and Morton, 1994; Deutch et al, 1987; Jentsch et al, 1997a; Kubota et al, 1999b; Murase et al, 1992), in turn preventing a neurochemical substrate that contributes to the deficits of spatial working memory. If this hypothesis were correct, then depletion of presynaptic noradrenaline levels (produced by DSP-4 administration) should have altered responsiveness to clonidine. This hypothesis was not supported by the current experiment, which instead indicated that the effects of PCP were diminished by noradrenaline depletion. Although these results do not resolve whether a presynaptic action of clonidine on noradrenergic systems is critical or not to its ameliorative effects against PCP-induced behavioral impairments, they do suggest that a releasable pool of noradrenaline participates in cognitive deficits elicited by NMDA antagonists. Studies using more substantial noradrenaline depletions will probably be required to firmly resolve this situation.

Role for alpha-2 receptor subtypes. The current results do not resolve the question of which alpha-2 receptor subtype(s) may be involved in the beneficial effects of clonidine and guanfacine in PCP-treated rats. In the brain, the alpha-2A receptor subtype is both pre- and postsynaptically localized, while the alpha-2B and alpha-2C receptor subtypes are largely postjunctional. Both alpha-2A and alpha-2C receptors are expressed in significant amounts in the neocortical and basal ganglia structures (Renouard et al, 1994; Uhlen et al, 1997b; Winzer-Serhan et al, 1997a,b) needed for efficient working memory performance (Bailey and Mair, 2004; Chudasama and Muir, 1997; Floresco et al, 1999; Mair et al, 2002; Seamans et al, 1998). In addition, alpha-2B receptors are expressed in thalamic nuclei (Tavares et al, 1996; Winzer-Serhan and Leslie, 1997), and dorsomedial and anterior nuclei of the thalamus also contribute substantially to performance (Bailey and Mair, 2004; Floresco et al, 1999). So far, both the alpha-2A and alpha-2C subtypes have been implicated in cognition, as reflected by deficiencies in working memory performance in 2A or 2C knockout mice (Franowicz et al, 2002; Tanila et al, 1999). Therefore, all three subtypes are positioned to modulate potentially working memory function. Further studies utilizing selective antagonists and/or knockout mice will be necessary to resolve which receptor subtype regulates $\mathrm{PCP}$-induced deficits of cognition.

Summary. Alpha-2 agonists are effective at reducing PCPinduced deficits of working memory in rats. Inasmuch as NMDA antagonist-induced cognitive deficits may 'model' aspects of neuropsychological impairments in schizophrenia (Chudasama and Robbins, 2004b; Jentsch and Roth, 1999; Krystal et al, 2002; Newcomer et al, 1999), these data may support further attempts to characterize the potential cognitive-enhancing effects of alpha-2 agonists in schizophrenia (Fields et al, 1988; Friedman et al, 2001). Indeed, accurate dissection of the subtype mechanisms involved may maximize the cognitive benefits of alpha-2 agonists while obviating the sedating and hypotensive side effects.

\section{ACKNOWLEDGEMENTS}

We gratefully acknowledge the technical assistance of FengPei Chen in conducting the HPLC analyses. These studies were supported by NIMH Grants R03-MH069360 (JDJ) and R01-MH057483 (RHR), as well as NCRR Grant P20RR020750 (JDJ).

\section{REFERENCES}

Aoki C, Go CG, Venkatesan C, Kurose H (1994). Perikaryal and synaptic localization of alpha 2A-adrenergic receptor-like immunoreactivity. Brain Res 650: 181-204.

Aoki C, Venkatesan C, Go CG, Forman R, Kurose H (1998). Cellular and subcellular sites for noradrenergic action in the monkey dorsolateral prefrontal cortex as revealed by the immunocytochemical localization of noradrenergic receptors and axons. Cereb Cortex 8: 269-277.

Bailey KR, Mair RG (2004). Dissociable effects of frontal cortical lesions on measures of visuospatial attention and spatial working memory in the rat. Cereb Cortex 14: 974-985.

Bowers Jr MB, Morton JB (1994). Regional brain catecholamines and metabolites following THC, PCP and MK-801. Prog Neuropsychopharmacol Biol Psychiatry 18: 961-964.

Carli M, Robbins TW, Evenden JL, Everitt BJ (1983). Effects of lesions to ascending noradrenergic neurones on performance of a 5-choice serial reaction task in rats; implications for theories of dorsal noradrenergic bundle function based on selective attention and arousal. Behav Brain Res 9: 361-380.

Chudasama Y, Dalley JW, Nathwani F, Bouger P, Robbins TW (2004). Cholinergic modulation of visual attention and working memory: dissociable effects of basal forebrain 192-IgG-saporin lesions and intraprefrontal infusions of scopolamine. Learn Mem 11: 78-86.

Chudasama Y, Muir JL (1997). A behavioural analysis of the delayed non-matching to position task: the effects of scopolamine, lesions of the fornix and of the prelimbic region on mediating behaviours by rats. Psychopharmacology (Berl) 134: 73-82.

Chudasama Y, Robbins TW (2004a). Dopaminergic modulation of visual attention and working memory in the rodent prefrontal cortex. Neuropsychopharmacology 29: 1628-1636.

Chudasama Y, Robbins TW (2004b). Psychopharmacological approaches to modulating attention in the five-choice serial reaction time task: implications for schizophrenia. Psychopharmacology (Berl) 174: 86-98.

Cooper JR, Bloom FE, Roth RH (2003). The Biochemical Basis of Neuropharmacology 8th edn. Oxford University Press: Oxford.

Deutch AY, Tam SY, Freeman AS, Bowers Jr MB, Roth RH (1987). Mesolimbic and mesocortical dopamine activation induced by phencyclidine: contrasting pattern to striatal response. Eur $J$ Pharmacol 134: 257-264.

Fields RB, Van Kammen DP, Peters JL, Rosen J, Van Kammen WB, Nugent A et al (1988). Clonidine improves memory function in schizophrenia independently from change in psychosis. Preliminary findings. Schizophr Res 1: 417-423.

Floresco SB, Braaksma DN, Phillips AG (1999). Thalamic-corticalstriatal circuitry subserves working memory during delayed responding on a radial arm maze. J Neurosci 19: 11061-11071.

Franowicz JS, Kessler LE, Borja CM, Kobilka BK, Limbird LE, Arnsten AF (2002). Mutation of the alpha2A-adrenoceptor impairs working memory performance and annuls cognitive enhancement by guanfacine. J Neurosci 22: 8771-8777.

Friedman JI, Adler DN, Temporini HD, Kemether E, Harvey PD, White L et al (2001). Guanfacine treatment of cognitive impairment in schizophrenia. Neuropsychopharmacology 25: 402-409. 
Grottick AJ, Higgins GA (2000). Effect of subtype selective nicotinic compounds on attention as assessed by the five-choice serial reaction time task. Behav Brain Res 117: 197-208.

Harkin A, Morris K, Kelly JP, O'Donnell JM, Leonard BE (2001). Modulation of MK-801-induced behaviour by noradrenergic agents in mice. Psychopharmacology (Berl) 154: 177-188.

Hertel P, Mathe JM, Nomikos GG, Iurlo M, Mathe AA, Svensson TH (1995). Effects of D-amphetamine and phencyclidine on behavior and extracellular concentrations of neurotensin and dopamine in the ventral striatum and the medial prefrontal cortex of the rat. Behav Brain Res 72: 103-114.

Javitt DC, Zukin SR (1991). Recent advances in the phencyclidine model of schizophrenia. Am J Psychiatry 148: 1301-1308.

Jentsch JD, Andrusiak E, Tran A, Bowers Jr MB, Roth RH (1997a). Delta 9-tetrahydrocannabinol increases prefrontal cortical catecholaminergic utilization and impairs spatial working memory in the rat: blockade of dopaminergic effects with HA966. Neuropsychopharmacology 16: 426-432.

Jentsch JD, Anzivino LA (2004). A low dose of the alpha(2) agonist clonidine ameliorates the visual attention and spatial working memory deficits produced by phencyclidine administration to rats. Psychopharmacology (Berl) 175: 76-83.

Jentsch JD, Elsworth JD, Redmond Jr DE, Roth RH (1997b). Phencyclidine increases forebrain monoamine metabolism in rats and monkeys: modulation by the isomers of HA966. J Neurosci 17: 1769-1775.

Jentsch JD, Roth RH (1999). The neuropsychopharmacology of phencyclidine: from NMDA receptor hypofunction to the dopamine hypothesis of schizophrenia. Neuropsychopharmacology 20: 201-225.

Jentsch JD, Wise A, Katz Z, Roth RH (1998). Alpha-noradrenergic receptor modulation of the phencyclidine- and delta9-tetrahydrocannabinol-induced increases in dopamine utilization in rat prefrontal cortex. Synapse 28: 21-26.

Kim SH, Price MT, Olney JW, Farber NB (1999). Excessive cerebrocortical release of acetylcholine induced by NMDA antagonists is reduced by GABAergic and alpha2-adrenergic agonists. Mol Psychiatry 4: 344-352.

Krystal JH, Anand A, Moghaddam B (2002). Effects of NMDA receptor antagonists: implications for the pathophysiology of schizophrenia. Arch Gen Psychiatry 59: 663-664.

Kubota T, Hirota K, Yoshida H, Takahashi S, Anzawa N, Ohkawa H et al (1999a). Effects of sedatives on noradrenaline release from the medial prefrontal cortex in rats. Psychopharmacology (Berl) 146: $335-338$

Kubota T, Hirota K, Yoshida H, Takahashi S, Ohkawa H, Anzawa N et al (1999b). Inhibitory effect of clonidine on ketamine-induced norepinephrine release from the medial prefrontal cortex in rats. Br J Anaesth 83: 945-947.

Lorrain DS, Schaffhauser H, Campbell UC, Baccei CS, Correa LD, Rowe B et al (2003). Group II mGlu receptor activation suppresses norepinephrine release in the ventral hippocampus and locomotor responses to acute ketamine challenge. Neuropsychopharmacology 28: 1622-1632.

Lowry OH, Rosebraugh NJ, Farr AL, Randall RJ (1954). Protein measurement with the folin phenol reagent. J Biol Chem 193: 265-275.

Mair RG, Koch JK, Newman JB, Howard JR, Burk JA (2002). A double dissociation within striatum between serial reaction time and radial maze delayed nonmatching performance in rats. J Neurosci 22: 6756-6765.

Malhotra AK, Pinals DA, Weingartner H, Sirocco K, Missar CD, Pickar D et al (1996). NMDA receptor function and human cognition: the effects of ketamine in healthy volunteers. Neuropsychopharmacology 14: 301-307.

Millan MJ, Lejeune F, Gobert A, Brocco M, Auclair A, Bosc C et al (2000). S18616, a highly potent spiroimidazoline agonist at alpha(2)-adrenoceptors: II. Influence on monoaminergic transmission, motor function, and anxiety in comparison with dexmedetomidine and clonidine. J Pharmacol Exp Ther 295: 1206-1222.

Moghaddam B, Adams B, Verma A, Daly D (1997). Activation of glutamatergic neurotransmission by ketamine: a novel step in the pathway from NMDA receptor blockade to dopaminergic and cognitive disruptions associated with the prefrontal cortex. J Neurosci 17: 2921-2927.

Murase S, Nisell M, Grenhoff J, Svensson TH (1992). Decreased sensory responsiveness of noradrenergic neurons in the rat locus coeruleus following phencyclidine or dizocilpine (MK-801): role of NMDA antagonism. Psychopharmacology (Berl) 109: 271-276.

Newcomer JW, Farber NB, Jevtovic-Todorovic V, Selke G, Melson AK, Hershey T et al (1999). Ketamine-induced NMDA receptor hypofunction as a model of memory impairment and psychosis. Neuropsychopharmacology 20: 106-118.

Newcomer JW, Krystal JH (2001). NMDA receptor regulation of memory and behavior in humans. Hippocampus 11: 529-542.

Newman-Tancredi A, Nicolas JP, Audinot V, Gavaudan S, Verriele L, Touzard M et al (1998). Actions of alpha2 adrenoceptor ligands at alpha2A and 5-HT1A receptors: the antagonist, atipamezole, and the agonist, dexmedetomidine, are highly selective for alpha2A adrenoceptors. Naunyn Schmiedebergs Arch Pharmacol 358: 197-206.

Rasmussen K, Fuller RW, Stockton ME, Perry KW, Swinford RM, Ornstein PL (1991). NMDA receptor antagonists suppress behaviors but not norepinephrine turnover or locus coeruleus unit activity induced by opiate withdrawal. Eur J Pharmacol 197: 9-16.

Renouard A, Widdowson PS, Millan MJ (1994). Multiple alpha 2 adrenergic receptor subtypes. I. Comparison of $\left[{ }^{3} \mathrm{H}\right] \mathrm{RX} 821002-$ labeled rat $\mathrm{R}$ alpha-2A adrenergic receptors in cerebral cortex to human $\mathrm{H}$ alpha2 $\mathrm{A}$ adrenergic receptor and other populations of alpha-2 adrenergic subtypes. J Pharmacol Exp Ther 270: 946-957.

Seamans JK, Floresco SB, Phillips AG (1998). D1 receptor modulation of hippocampal-prefrontal cortical circuits integrating spatial memory with executive functions in the rat. J Neurosci 18: 1613-1621.

Swanson CJ, Schoepp DD (2003). A role for noradrenergic transmission in the actions of phencyclidine and the antipsychotic and antistress effects of mGlu2/3 receptor agonists. Ann NY Acad Sci 1003: 309-317.

Tanila H, Mustonen K, Sallinen J, Scheinin M, Riekkinen Jr P (1999). Role of alpha2C-adrenoceptor subtype in spatial working memory as revealed by mice with targeted disruption of the alpha2C-adrenoceptor gene. Eur J Neurosci 11: 599-603.

Tavares A, Handy DE, Bogdanova NN, Rosene DL, Gavras H (1996). Localization of alpha 2A- and alpha 2B-adrenergic receptor subtypes in brain. Hypertension 27: 449-455.

Tellez S, Colpaert F, Marien M (1999). Alpha2-adrenoceptor modulation of cortical acetylcholine release in vivo. Neuroscience 89: 1041-1050.

Uhlen S, Lindblom J, Johnson A, Wikberg JE (1997a). Autoradiographic studies of central alpha 2A- and alpha 2C-adrenoceptors in the rat using $\left[{ }^{3} \mathrm{H}\right] \mathrm{MK} 912$ and subtype-selective drugs. Brain Res 770: 261-266.

Uhlen S, Lindblom J, Tiger G, Wikberg JE (1997b). Quantification of alpha2 $\mathrm{A}$ and alpha2C adrenoceptors in the rat striatum and in different regions of the spinal cord. Acta Physiol Scand 160: 407-412.

Uhlen S, Muceniece R, Rangel N, Tiger G, Wikberg JE (1995). Comparison of the binding activities of some drugs on alpha $2 \mathrm{~A}$, alpha $2 \mathrm{~B}$ and alpha 2C-adrenoceptors and non-adrenergic imidazoline sites in the guinea pig. Pharmacol Toxicol 76: 353-364.

Verma A, Moghaddam B (1996). NMDA receptor antagonists impair prefrontal cortex function as assessed via spatial delayed 
alternation performance in rats: modulation by dopamine. J Neurosci 16: 373-379.

Wenk G, Hughey D, Boundy V, Kim A, Walker L, Olton D (1987). Neurotransmitters and memory: role of cholinergic, serotonergic, and noradrenergic systems. Behav Neurosci 101: 325-332.

Winzer-Serhan UH, Leslie FM (1997). Alpha2B adrenoceptor mRNA expression during rat brain development. Brain Res Dev Brain Res 100: 90-100.
Winzer-Serhan UH, Raymon HK, Broide RS, Chen Y, Leslie FM (1997a). Expression of alpha 2 adrenoceptors during rat brain development - I. Alpha 2A messenger RNA expression. Neuroscience 76: 241-260.

Winzer-Serhan UH, Raymon HK, Broide RS, Chen Y, Leslie FM (1997b). Expression of alpha 2 adrenoceptors during rat brain development-II. Alpha 2C messenger RNA expression and $\left[{ }^{3} \mathrm{H}\right]$ rauwolscine binding. Neuroscience 76: 261-272. 